\title{
Experimental Evaluation of Microwave Antenna for Thermal Treatment of Bile Duct Carcinoma
}

\author{
KOUSUKE TSUBOUCHI ${ }^{*}$, KAZUYUKI SAITO ${ }^{2}$, MASAHARU TAKAHASHI ${ }^{2}$, \\ KOICHI ITO ${ }^{1}$, TOSHIO TSUYUGUCHI ${ }^{3}$, TAKETO YAMAGUCHI ${ }^{4}$, \\ KAZUKI KATO ${ }^{5}$
}

\author{
${ }^{1}$ Graduate School of Engineering, Chiba University, 1-33 Yayoi-cho, Inage-ku, Chiba 263-8522, Japan \\ ${ }^{2}$ Research Center for Frontier Medical Engineering, Chiba University, 1-33 Yayoi-cho, Inage-ku, Chiba 263-8522, \\ Japan \\ ${ }^{3}$ Graduate School of Medicine, Chiba University, 1-8-1 Inohana, Chuo-ku, Chiba 260-8670, Japan \\ ${ }^{4}$ Chiba Cancer Center, 666-2 Nitona-cho, Chuo-ku, Chiba 260-8717, Japan \\ ${ }^{5}$ Funabashi Central Hospital, 6-13-10 Kaijin-cho, Funabashi 273-8556, Japan
}

\begin{abstract}
A thermal treatment method that involves the use of an endoscope equipped with a microwave antenna is recognized as a new therapeutic method for treating bile duct carcinomas. In this treatment, the antenna is inserted into the bile duct through the papilla of Vater noninvasively using the forceps channel of the endoscope, and then, the part of the bile duct that has to be treated is locally heated. The antenna consists of a flexible coaxial cable, and microwave energy is radiated from the antenna slot at the tip. We have evaluated the heating performance of the antenna by heating the extracted organs using the antenna. In order to investigate the effectiveness and safety of this thermal treatment for clinical use, we carried out an animal experiment for evaluating the operability and robustness of the antenna and studying whether the temperature of the bile duct could be increased to $42^{\circ} \mathrm{C}$ without any tissue coagulation around the antenna slot under the blood flow condition. In the experiment, first, we inserted the antenna into the bile duct invasively by passing it through the duodenum. Next, we used X-ray images to adjust the position of an optical fiber thermosensor such that the distance between the slot of the antenna and the point at which the temperature was measured was not very large. As a result of the measurement, when an input power of $15 \mathrm{~W}$ was supplied to the antenna and the irradiating microwave was in the "on" state for $20 \mathrm{~s}$ and "off" state for $5 \mathrm{~s}$, the temperature could be maintained at $42^{\circ} \mathrm{C}$ without any tissue coagulation by using the antenna for $30 \mathrm{~min}$. The measured temperature position was located at the distance of $4.8 \mathrm{~mm}$ from the antenna slot. In addition, it was confirmed that the antenna was sufficiently robust, as it did not break down during the experiment. Therefore, we concluded that the antenna is suitable for use in thermal therapy. Further, we also analyze by using numerical simulation, in which the blood flow rate was $2.33 \times 10^{-5} \mathrm{~m}^{3} / \mathrm{kg} \bullet \mathrm{s}$, where the simulation results agreed well with the experimental results. Since the value of the blood flow rate was not quite different
\end{abstract}

Received 22 August, 2010, Accepted 4 December, 2010. *Corresponding author; Tel, +81-43-290-3931; Fax, +81-43-290-3933; e-mail, k.tsubouchi@graduate.chiba-u.jp

doi : $10.3191 /$ thermalmed.26.121

(C) 2010 Japanese Society for Thermal Medicine 
Thermal Med, 26 [4] : 121-130, 2010.

with the reference, the result was considered reasonable. Therefore the analytical model employed in this study can be used for improving the antenna structure and evaluating the therapeutic modality.

Key Words : bile duct carcinoma, microwave heating, coaxial-slot antenna, endoscope

\section{Introduction}

Microwave hyperthermia is a thermal treatment method for treating localized tumors. For carrying out intracavitary heating, an antenna is inserted into the tumor and microwave energy is radiated by the antenna directly to the target ${ }^{1,2}$. Thus, the tumor is heated effectively. The heating distribution varies according to the type of antenna used ; the coaxial-slot antenna ${ }^{3)}$, dipole antenna ${ }^{4}$, and helical antenna ${ }^{5,6}$ are some examples of antennas that can be used.

The authors have been studying the use of an endoscope equipped with a microwave antenna for thermal treatment of bile duct carcinomas ${ }^{3)}$. The antenna is thin and flexible. Moreover, the area that is heated can be controlled by varying the number or position of the antenna slots and localized heating in a specified region around the slot of the antenna can be realized. Therefore, the antenna is expected to be useful for treating various types of tumors. This noninvasive treatment is effective for treating unresectable bile duct carcinoma. The authors evaluated the thermal performance of the antenna by studying the heating of extracted liver tissue using the antenna ${ }^{7)}$. Interstitial coaxial-slot antennas have already been used in clinical treatments ${ }^{8,9)}$; however, it of intracavitary type in this paper is still in fundamental study.

This paper describes the effectiveness and safety of the thermal treatment method involving the use of a coaxial-slot antenna for intracavitary treatment. Since the effect of blood flow cannot be determined using extracted liver tissue, an animal experiment was conducted. First, the result of the animal experiment is described. In this experiment, the increase in the temperature of the microwave-irradiated bile duct of a swine was measured, and the operability and robustness of the antenna was confirmed. No tissue coagulation was observed in the bile duct when the antenna was used; this further confirms the suitability of the antenna for thermal therapy. Next, the results of numerical simulation performed using a simple model while taking into consideration blood flow are described. The blood flow in the deep part cannot be directly measured. Therefore, the results obtained in this study can be effectively used to estimate blood flow by performing a numerical calculation.

\section{Materials and methods}

\section{Structure of the antenna}

In many cases, the strictures of bile ducts can be dilated by stent placement. However, a new treatment method is needed to prevent restenosis that may occur after stenting. Fig. 1 shows a scheme of the thermal therapy for bile duct carcinoma; the scheme involves the use of an endoscope equipped with a microwave antenna. In this treatment, first, an endoscope equipped with a long flexible microwave antenna in its forceps channel is inserted noninvasively into the duodenum. Then, the antenna is guided into the bile duct through the papilla of Vater, which is located in the duodenum, by the forceps channel of the endoscope. Finally, the target tumor is locally heated by the radiated 
microwave energy.

Fig. 2 shows the structure of a microwave coaxial-slot antenna ${ }^{10)}$. The antenna consists of a flexible coaxial cable so that it can be easily operated when it is inserted into the endoscope. An antenna slot is cut out on the shield of the coaxial cable, and a short circuit occurs between the conductor and the shield of the tip of the antenna. Only the tissue near the tip of the coaxial-slot antenna will be heated. Moreover, a thermocouple is provided at the center of the slot. The heating pattern around the antenna can be controlled by varying the slot parameters such as the number, position, and width of the slots. In this study, an antenna with only one slot is used.

\section{Computer simulation for analyzing the experimental result}

The authors carried out a numerical simulation to analyze the results of the animal experiment. In this simulation, factors such as the cooling effect of the blood were taken into account ${ }^{8,11)}$. Fig. 3 shows a flowchart for the computer simulation performed to analyze the temperature distribution in biological tissue. First, the electric field around the antenna is calculated using computational electromagnetic techniques such as the FDTD (Finite-Difference Time-Domain) method, and then the SAR (Specific Absorption Rate) is calculated using the obtained value of the electric field and the following equation (the definition of SAR in

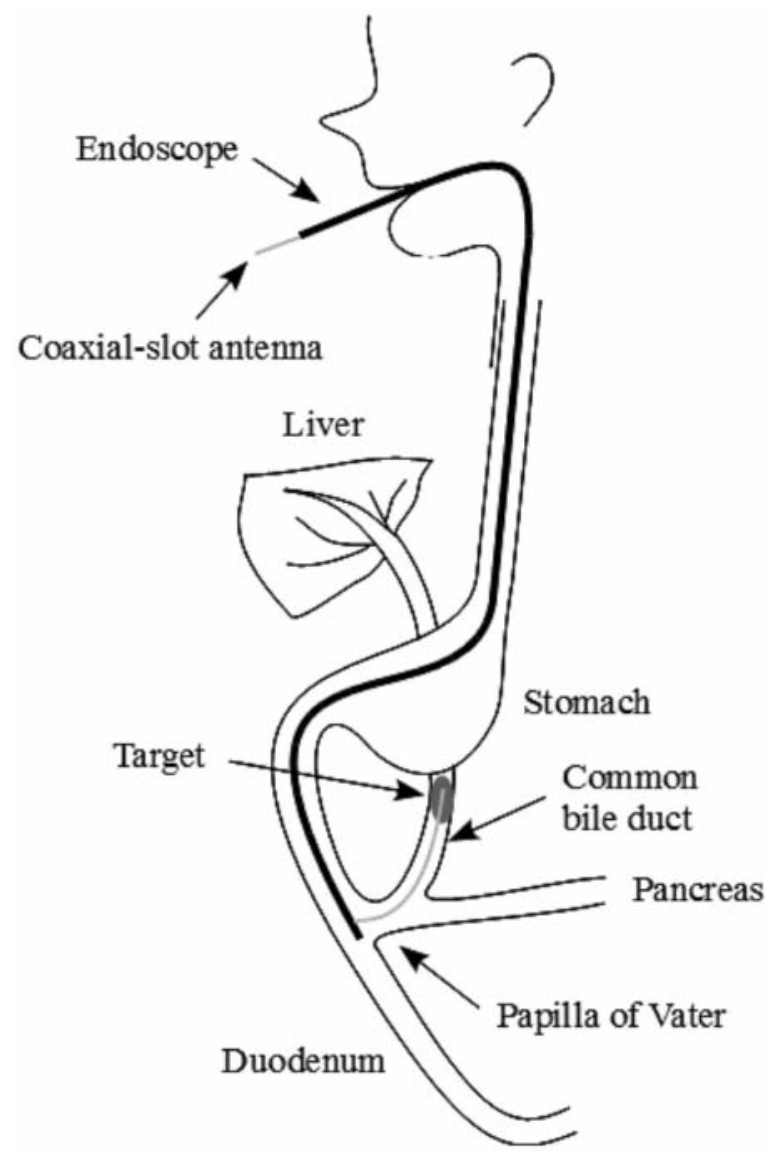

Fig. 1. Scheme of the thermal treatment of bile duct carcinoma which combined with the endoscope and the microwave antenna.

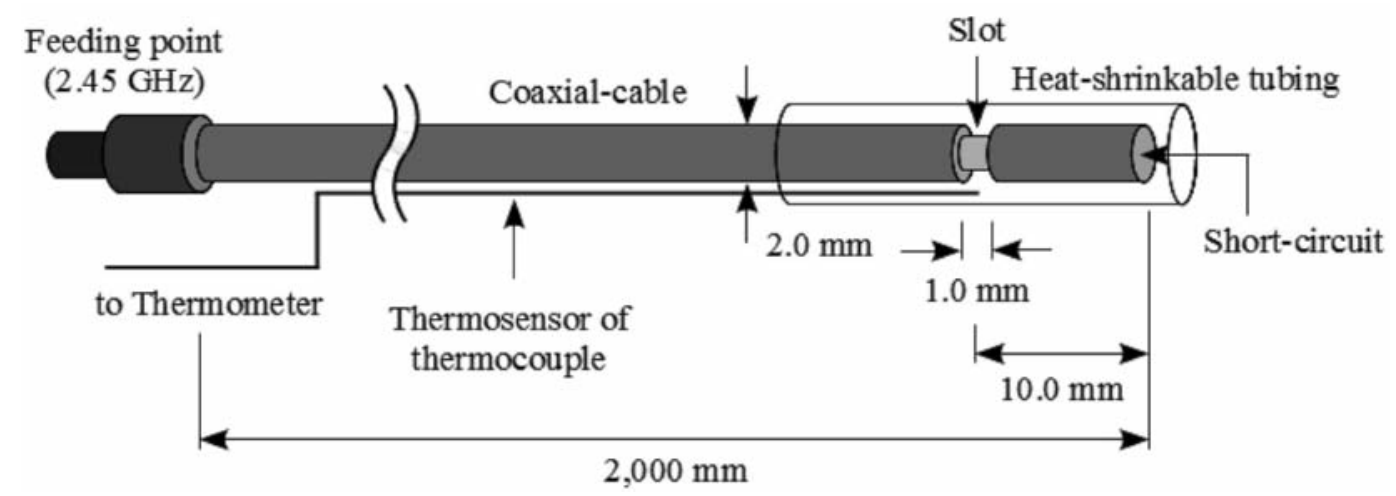

Fig. 2. Structure of a microwave antenna. 
terms of the electromagnetic field) :

$$
\mathrm{SAR}=\frac{\sigma}{\rho} E^{2}
$$

Here, $\sigma$ is the conductivity of the tissue $[\mathrm{S} / \mathrm{m}], \rho$ is the density of the tissue $\left[\mathrm{kg} / \mathrm{m}^{3}\right]$, and $\mathrm{E}$ is the electric field $(\mathrm{rms})[\mathrm{V} / \mathrm{m}]$. The value of SAR is proportional to the square of the electric field generated around the antenna and is equivalent to the heating source created by the electric field in the biological tissue.

Then, the temperature distribution around the antenna is evaluated. In order to obtain the temperature distribution in the biological tissue, the bioheat transfer equation ${ }^{12)}$, which includes the obtained SAR value, is numerically analyzed. The bioheat transfer equation is given by

$$
\rho c \frac{\partial T}{\partial t}=\varkappa \nabla^{2} T-\rho \rho_{b} c_{b} F\left(T-T_{b}\right)+\rho \cdot \mathrm{SAR}
$$

Here, $T$ is the temperature of the tissue $\left[{ }^{\circ} \mathrm{C}\right], t$ is the time $[\mathrm{s}], \rho$ is the density of the tissue $\left[\mathrm{kg} / \mathrm{m}^{3}\right], c$ is the specific heat of the tissue $[\mathrm{J} / \mathrm{kg} \cdot \mathrm{K}], \varkappa$ is the thermal conductivity $[\mathrm{W} / \mathrm{m} \cdot \mathrm{K}], \rho_{b}$ is the density of the blood $\left[\mathrm{kg} / \mathrm{m}^{3}\right], c_{b}$ is the specific heat of the blood $[\mathrm{J} / \mathrm{kg} \cdot \mathrm{K}], T_{b}$ is the temperature of the blood $\left[{ }^{\circ} \mathrm{C}\right]$

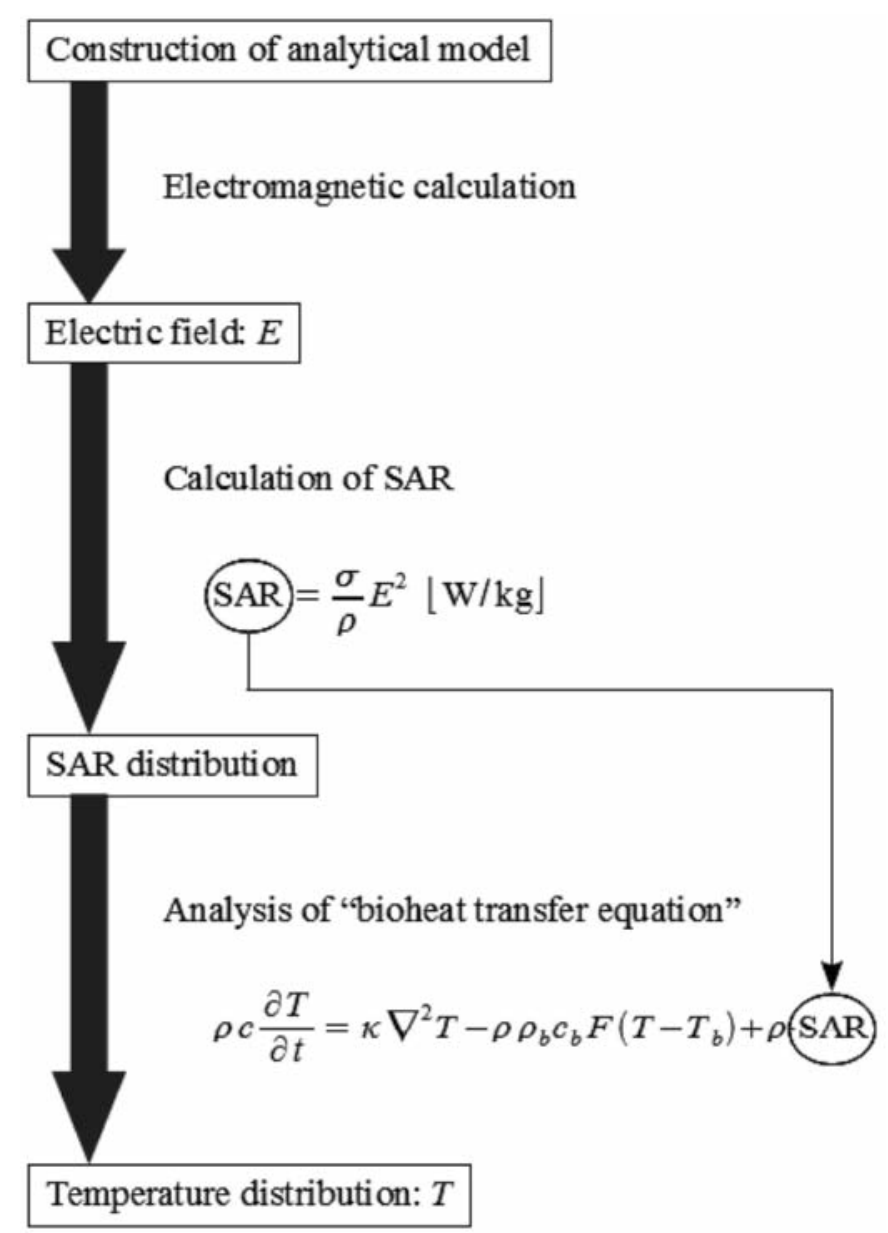

Fig. 3. Flowchart of numerical simulation. 
and $F$ is the blood flow rate $\left[\mathrm{m}^{3} / \mathrm{kg} \bullet \mathrm{s}\right]$. The SAR value of each point in analytical region is assigned into Eq. (2), and the temperature increase is calculated by the finite difference method in time domain.

Fig. 4 shows the FDTD calculation model for the coaxial-slot antenna. The coaxial-slot antenna is inserted into the bile duct that has a diameter of $5 \mathrm{~mm}$ and is filled with bile. The temperature was measured at a point that was located at a distance of $5 \mathrm{~mm}$ from the antenna slot.

A sinusoidal electric field was applied between the inner and outer conductors of the coaxial cable and then a steady-state analysis was carried out. The parameters used in the FDTD calculations are listed in Table I, and the properties of the biological tissues are listed in Table $\mathrm{II}^{13,14)}$. The cell size of $x$ and $y$ is $0.05 \mathrm{~mm}$ around the antenna, and it increased gradually with distance from the antenna. Further, in the calculations, nonreflective boundary condition of Mur 1st order is used.

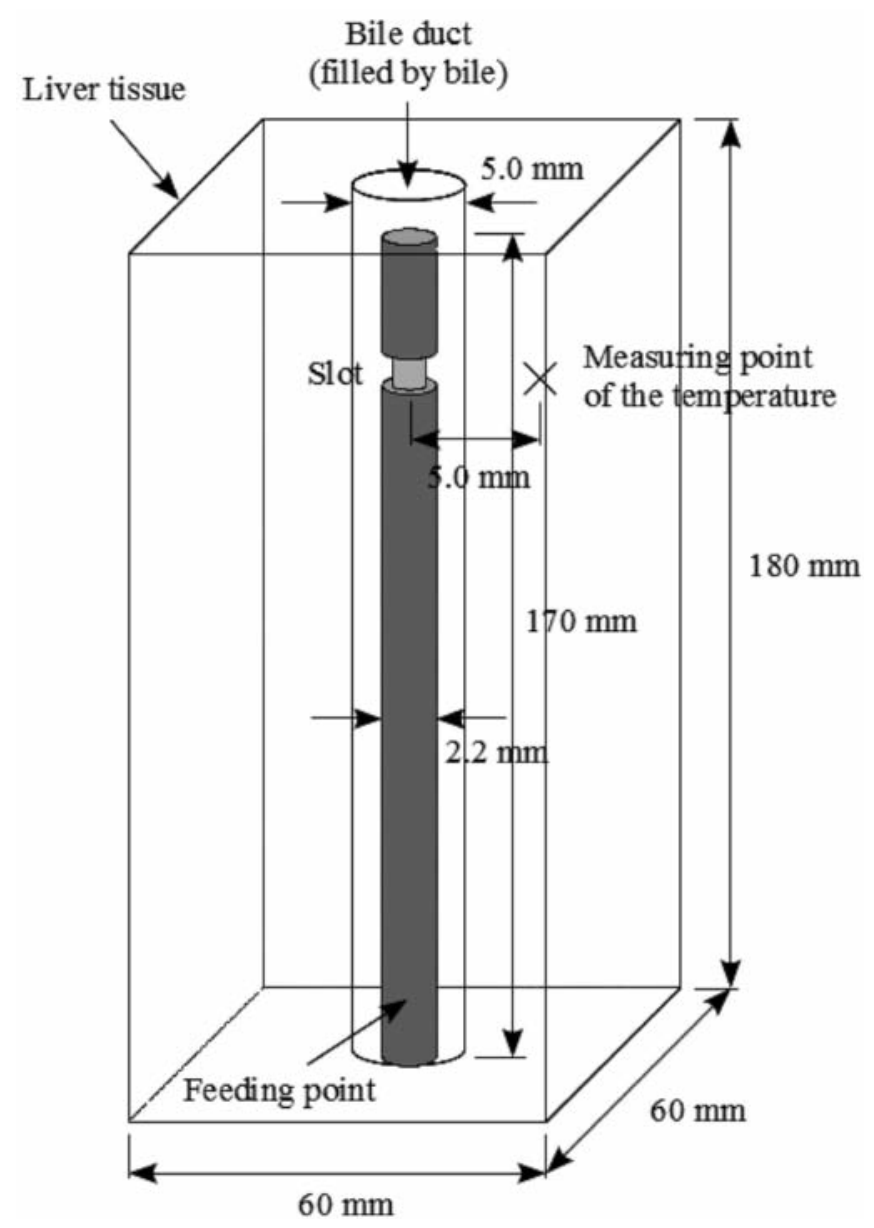

Fig. 4. Calculation model.

Table I. Parameters for FDTD calculations.

\begin{tabular}{|l|l|l|}
\hline $\begin{array}{l}\text { Cell size }[\mathrm{mm}] \\
\text { (minimum) }\end{array}$ & $\begin{array}{c}\Delta x, \Delta y \\
\Delta z\end{array}$ & $\begin{array}{l}0.05 \\
1.0 \text { (const.) }\end{array}$ \\
\hline $\begin{array}{c}\text { Cell size }[\mathrm{mm}] \\
\text { (maximum) }\end{array}$ & $\begin{array}{c}\Delta x, \Delta y \\
\Delta z\end{array}$ & 1.5 \\
\hline Time step [ps] & 1.0 (const.) \\
\hline Absorbing boundary condition & 0.117 \\
\hline
\end{tabular}

Table II. Physical properties of the biological tissues.

\begin{tabular}{|l|c|c|c|c|c|}
\hline Tissue & $\begin{array}{l}\text { Relative } \\
\text { permittivity }\end{array}$ & $\begin{array}{l}\text { Conductivity } \\
{[\mathrm{S} / \mathrm{m}]}\end{array}$ & $\begin{array}{l}\text { Density } \\
{\left[\mathrm{kg} / \mathrm{m}^{3}\right]}\end{array}$ & $\begin{array}{l}\text { Specific heat } \\
{[\mathrm{J} / \mathrm{kg} \cdot \mathrm{K}]}\end{array}$ & $\begin{array}{c}\text { Thermal } \\
\text { conductivity } \\
{[\mathrm{W} / \mathrm{m} \cdot \mathrm{K}]}\end{array}$ \\
\hline Liver & 43.0 & 1.69 & 1,030 & 3,600 & 0.497 \\
\hline Bile & 68.4 & 2.80 & 1,010 & 3,960 & 0.500 \\
\hline Blood & - & - & 1,058 & 3,960 & - \\
\hline
\end{tabular}




\section{Experimental procedure}

Fig. 5 shows the experimental system used in the animal experiment. The swine used in the experiment was three-months-old and weighed $49.15 \mathrm{~kg}$. In actual treatment, an antenna is inserted noninvasively with an endoscope. However, in the experiment, the detection of the papilla of Vater of the swine with the endoscope was difficult. Therefore, in the experiment, the antenna was inserted invasively at laparotomy.

First, the resupine swine was given a general anesthetic. In order to prevent the loss of body heat in the experiment, electric blanket was put at the swine back. Then, an incision was made in the duodenum, and an orifice was created on the mucosal side of the digestive tract to insert the antenna into the bile duct, and the antenna was inserted into the bile duct through the papilla of Vater. Microwave frequency was given at $2.45 \mathrm{GHz}$, where its energy was measured by using a microwave power reflection meter. Moreover, the temperature of the outer surface of the bile duct was measured by using an optical fiber thermosensor and a thermocouple on the antenna. An optical fiber thermosensor was inserted into a thin and long catheter. In the experiment, we investigated whether the temperature of the bile duct could be increased to $42^{\circ} \mathrm{C}$ without any tissue coagulation around the antenna slot. Therefore, the position of the thermosensor was adjusted in close distance to the antenna slot.

Following the experiment, the distance between the antenna and the thermosensor was calculated using X-ray images, which was produced at different angles.

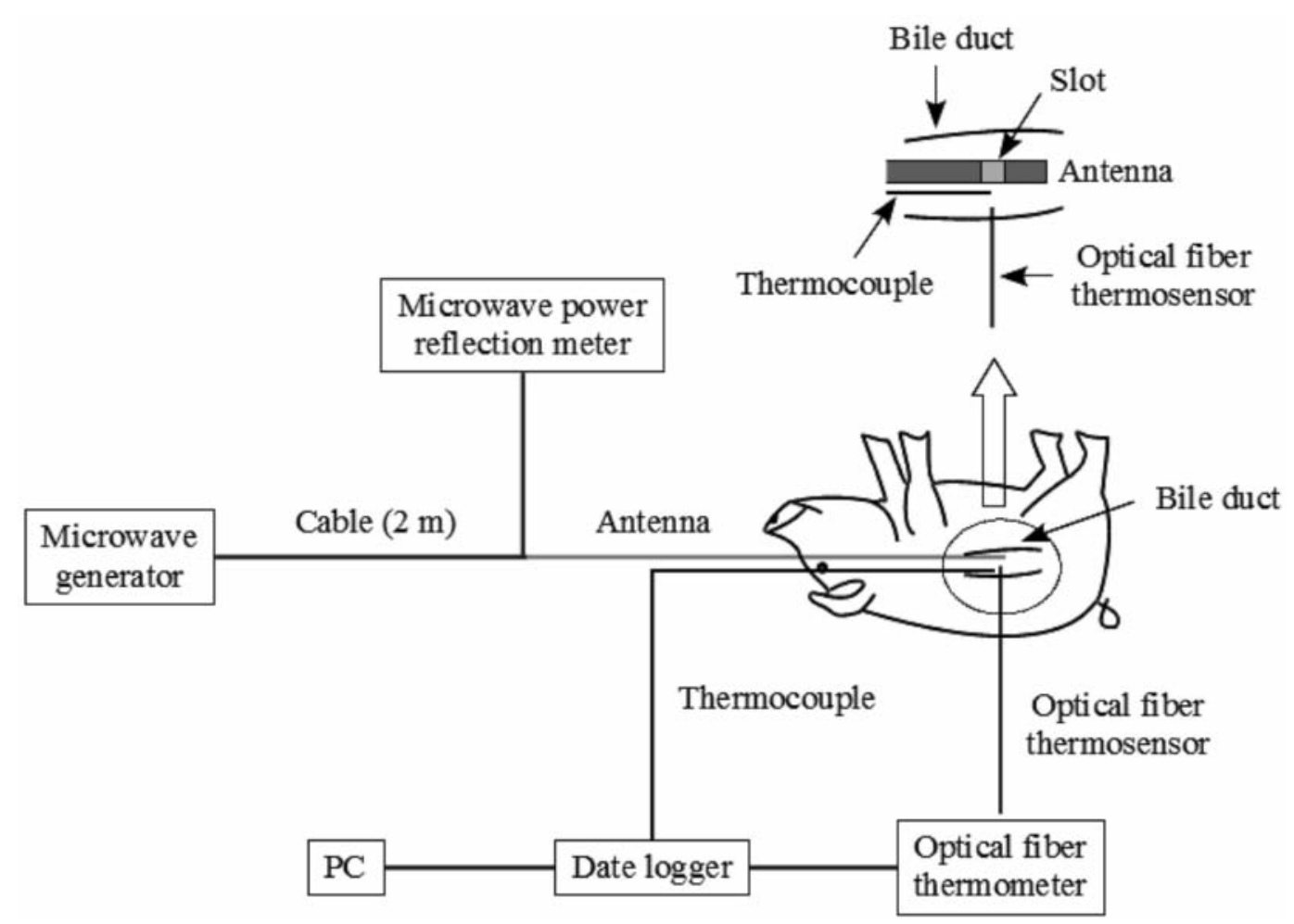

Fig. 5. Experimental system. 


\section{Results}

Fig. 6 shows the result of the experiment, and Table III lists the properties of the radiated microwaves. In Fig. 6a, the temperatures measurement by using the optical fiber and the thermocouple are shown. Here, temperature at each time instant was measured by using the thermocouple during no microwave irradiation a period of $2 \mathrm{~s}$ so that electromagnetic interference could be avoided.

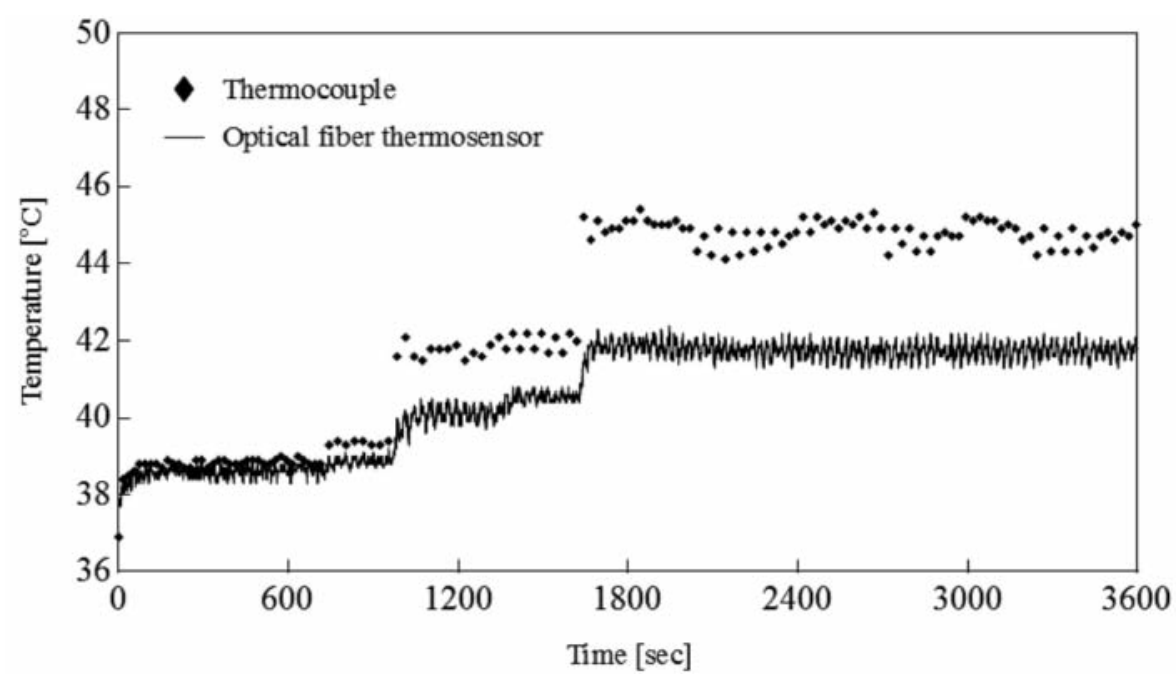

(a) Temperature measurement by thermocouple and optical fiber thermosensor.

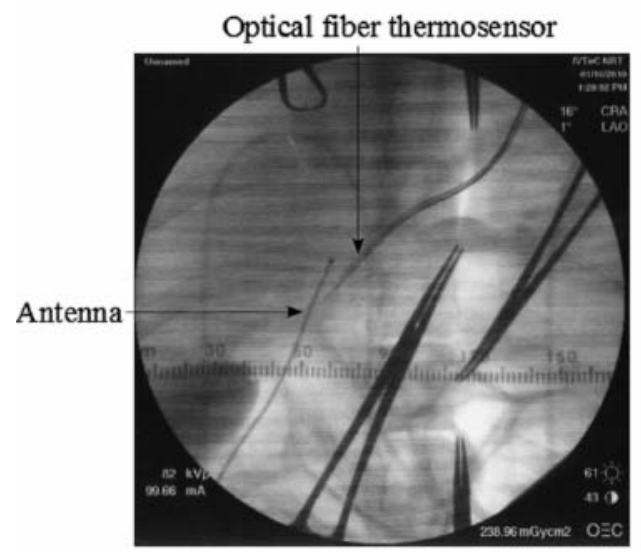

(b) X-ray picture of the thermal area.

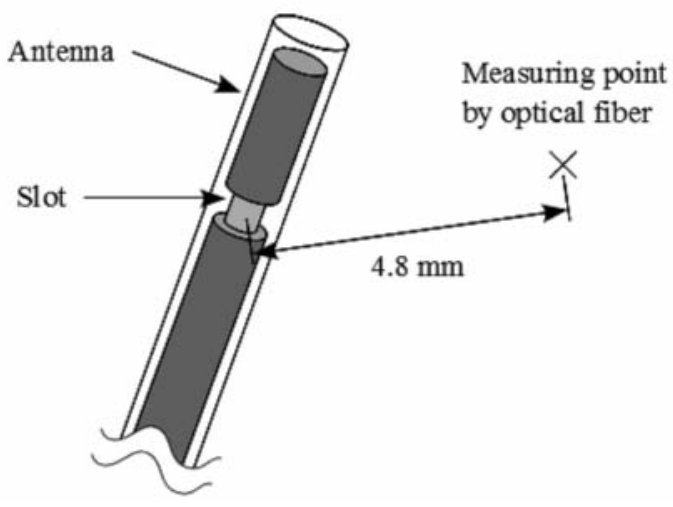

(c) Distance between the antenna slot and optical fiber thermosensor.

Fig. 6. Result of the experiment.

Table III. Condition of time interval of irradiating microwave.

\begin{tabular}{|c|c|c|c|}
\hline Time $[\mathrm{s}]$ & Input power $[\mathrm{W}]$ & On $[\mathrm{s}]$ & Off $[\mathrm{s}]$ \\
\hline $0-720$ & 5 & 10 & 10 \\
\hline $721-960$ & 5 & 20 & 10 \\
\hline $961-1,340$ & 10 & 20 & 10 \\
\hline $1,341-1,620$ & 10 & 20 & 5 \\
\hline $1,621-3,600$ & 15 & 20 & 5 \\
\hline
\end{tabular}


First, microwave irradiation was carried out by supplying $5 \mathrm{~W}$ of input power to the antenna, and microwave irradiation was carried out for $10 \mathrm{~s}$ and stopped for $10 \mathrm{~s}$. In reference 7, the authors conducted an experiment on extracted liver tissue. In their experiment, the increase in the temperature around the slot was observed to be more than $10^{\circ} \mathrm{C}$ when $4.8 \mathrm{~W}$ of input power was supplied to the antenna and continuous irradiation was carried out for $10 \mathrm{~min}$. Therefore, the irradiation power and the time period during which irradiation was carried out were adjusted to prevent tissue coagulation. However, the temperature of the bile duct increased to only $38.8^{\circ} \mathrm{C}$ after $720 \mathrm{~s}$. Therefore, the input power and time interval were adjusted gradually such that the temperature of the tissue could be increased to $42^{\circ} \mathrm{C}$. When $15 \mathrm{~W}$ of input power was supplied to the antenna and microwave irradiation was carried out for $20 \mathrm{~s}$ and stopped for $5 \mathrm{~s}$, the temperature of the tissue increased to $42^{\circ} \mathrm{C}$, and the tissue was heated under these conditions for $30 \mathrm{~min}$. In addition, the antenna did not break down during the experiment. Following the experiment, the distance between the antenna slot and the optical fiber thermosensor was calculated by using X-ray images, resulting $4.8 \mathrm{~mm}$ (Figs. 6b and 6c). In addition, the authors visually confirmed that after the experiment, tissue coagulation did not occur.

\section{Discussion}

The authors carried out an animal experiment for observing the influence of blood flow in the deep part under microwave irradiation of the bile duct. Further, numerical simulation was carried out, and the authors evaluated the influence of blood flow by simulating a steady state for more than 1,620 s (Fig. 6). Fig. 7 shows the calculated results. The temperature was measured at a point that was located at a distance of $5 \mathrm{~mm}$ from the antenna slot, and the initial temperature of the tissues was $40.5^{\circ} \mathrm{C}$. For the case in which the blood flow rate was $2.33 \times 10^{-5} \mathrm{~m}^{3} / \mathrm{kg} \cdot \mathrm{s}$, the analytical result was approximately in

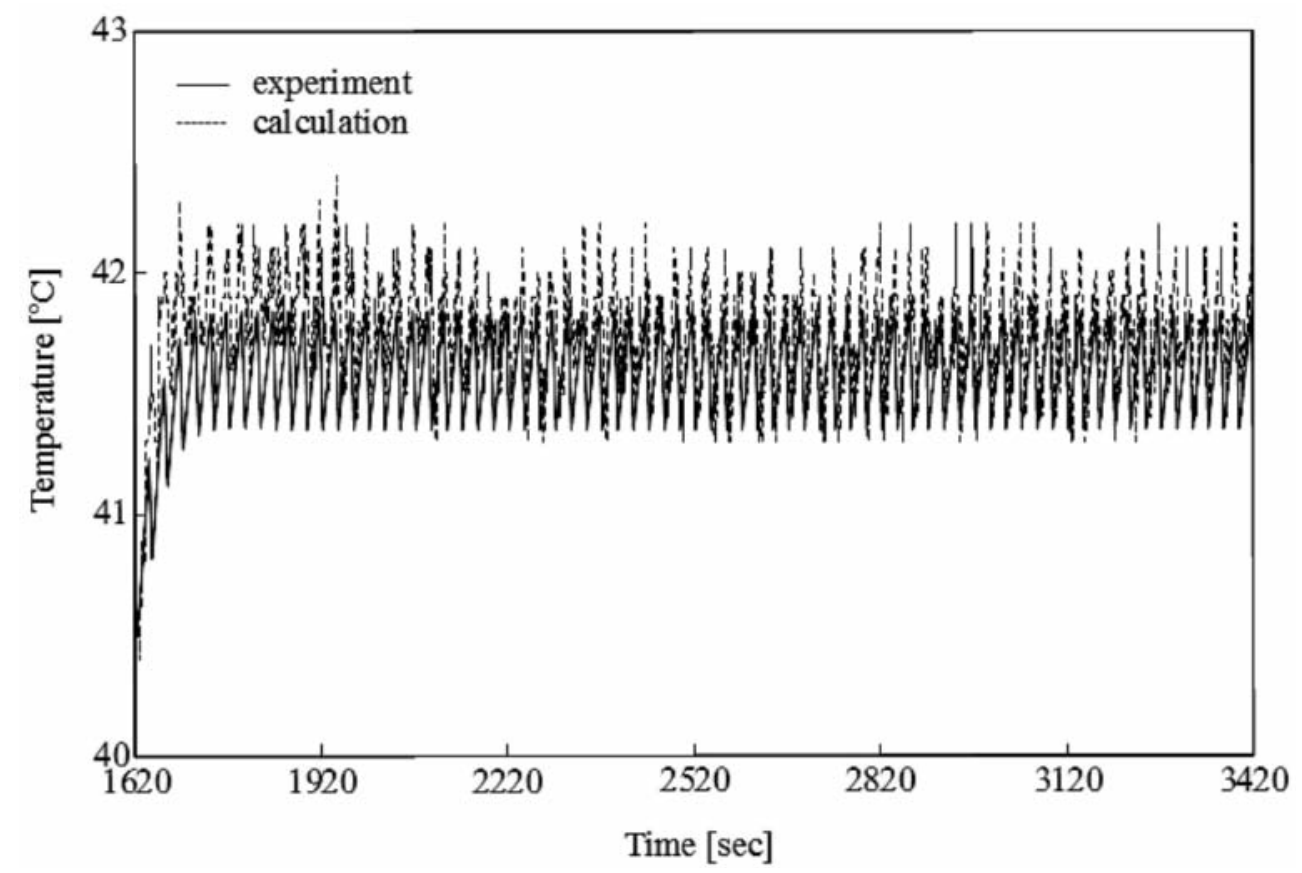

Fig. 7. Analytical result of the blood flow in animal experiment. 
agreement with the result of the animal experiment. In references 13 and 14, the blood flow rate of the liver tissue is $1.67 \times 10^{-5} \mathrm{~m}^{3} / \mathrm{kg} \cdot \mathrm{s}$. The blood flow rate of the analytical result was not quite different with the references. Therefore, this analytical result was considered reasonable.

Fig. 8 shows the calculation results of considering the difference of the blood flow rate. When the blood flow was neglected, the temperature increased to $75^{\circ} \mathrm{C}$. Thus, the result showed that the influence of blood flow on the increase of the temperature was considerably large. Moreover, in this experiment, the blood flow rate was ten times higher than that of reference 9. This high flow rate can be understood with the fact that the bile duct is near the liver and the blood flow rate was high around the liver.

In this calculation, an homogeneous medium and the value of human body were used; therefore, this model was considerably simpler when compared to the experiment conducted on a swine. However, the blood flow in the deep part cannot be directly measured. Therefore, further study on the improvement of the antenna structure and on the therapeutic modality must be carried out.

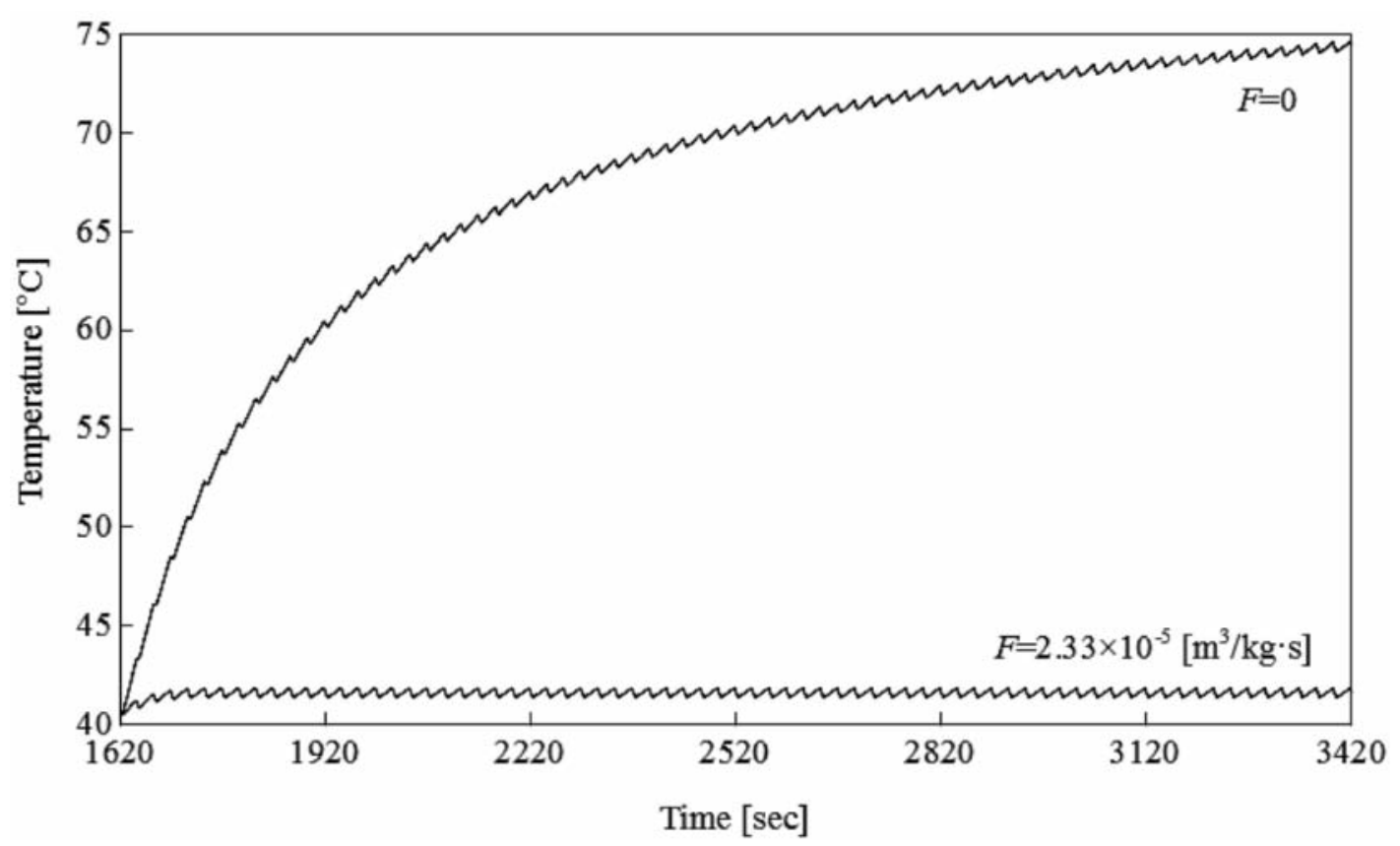

Fig. 8. Analytical result of temperature rise considered the difference of the blood flow.

\section{Conclusion}

In this paper, the experimental evaluation of microwave antenna for use in thermal treatment of bile duct carcinoma is described. The temperature could be maintained at $42^{\circ} \mathrm{C}$ for 30 min without any tissue coagulation by carrying out irradiation of the bile duct of a swine when an input power of $15 \mathrm{~W}$ was supplied to the antenna and the microwave irradiation was carried out for $20 \mathrm{~s}$ and stopped for $5 \mathrm{~s}$; this indicates that the antenna was effective for use in thermal therapy. In addition, we confirmed that the antenna is operable and robust. Moreover, we confirmed that the blood flow around the bile duct significantly affected the increase in the temperature. Moreover, we carried out the numerical simulation and evaluated the influence of blood flow by conducting an animal experiment. The calculated blood 
Thermal Med, 26 [4] : 121-130, 2010.

flow rate is more than ten times that in reference 9 ; this high flow rate can be attributed to the fact that the bile duct is near the liver and the blood flow rate is high around the liver. In this calculation, homogeneous medium and the value of human body were used; therefore, this model was considerably simpler than the swine used in the experiment. However, the analytical model was useful for improving the structure of the antenna and for investigating the therapeutic modality.

\section{Acknowledgment}

This work was supported by the Japan Society for the Promotion of Science, Grant-in-Aid for Young Scientists (B) 22760242.

\section{References}

1) Kikuchi M.: Heating principle and heating device for clinical. "Hyperthermia manual" Ed. T. Matsuda, Maguburosu-syuppan, pp.7-17, 1991. (Japanese).

2) Lin J.C., Wang Y.-J. : Interstitial microwave antennas for thermal therapy. Int J Hyperthermia, 3 : 37-47, 1987.

3) Saito K., Hiroe A., Kikuchi S., Takahashi M., Ito K. : Estimation of heating performances of a coaxial-slot antenna with endoscope for treatment of bile duct carcinoma. IEEE Trans Micow Theory Tech, 54: 3443-3449, 2006.

4) Broschat L.S., Chou C.-K., Luk H.K., Guy W.A., Ishimaru A.: An insulated dipole applicator for intracavitary hyperthermia. IEEE Trans Biomed Eng, 35: 173-177, 1988.

5) Astrahan M., Imanaka K., Jozsef G., Ameye F., Baert L., Sapozink M.D., Boyd S., Petrovich Z. : Heating characteristics of a helical microwave applicator for transurethral hyperthermia of benign prostatic hyperplasia. Int J Hyperthermia, 7: 141-155, 1991.

6) Liu R.L., Zhang E.Y., Gross E.J., Cetas T.C.: Heating pattern of helical microwave intracavitary oesophageal applicator. Int J Hyperthermia, $7:$ 577-586, 1991.

7) Saito K., Tsubouchi K., Takahashi M., Ito K. : Intracavitary microwave thermal therapy for bile duct carcinoma experimental evaluations on heating performances of antenna. International Workshop on Antenna Technology 2010 (iWAT 2010), Lisbon, Portugal, Mar. 2010.

8) Saito K., Aoyagi Y., Ito K., Horita H. : Interstitial microwave hyperthermia using coaxial-slot antennas-clinical trials based on numerical calculations of heating patterns-. Jpn J Hyperthermic Oncol, 21 : 237-245, 2005.

9) Ito K., Saito K., Yoshimura H., Aoyagi Y., Horita H. : Coaxial-slot antenna for interstitial microwave thermal therapy and its application to clinical trial. Proc IEEE EMBS : 2526-2529, 2004.

10) Ito K., Ueno K., Hyodo M., Kasai H.: Interstitial applicator composed of coaxial ring slots for microwave hyperthermia. Proc Int Symp Antennas Propagation, 2 : 253-256, 1989.

11) Tange Y., Saitoh Y., Kanai Y., Hori J.: Fundamental heating characteristics of an RF hyperthermic system using a rectangular resonant cavity applicator for deep-seated tumors. Jpn J Hyperthermic Oncol, 22 : 1-11, 2006.

12) Penns H.H. : Analysis of tissue and arterial blood temperatures in the resting human forearm. J Appl Phys, $1: 93-122$, 1948.

13) Duck F.A. : Electrical properties of tissue. "Physical Properties of Tissue" Ed. F.A. Duck, New York: Academic, pp. 167-223, 1990.

14) van den Berg P.M., De Hoop A.T., Segal A., Praagman N. : A computational model of the electromagnetic heating of biological tissue with application to hyperthermic therapy. IEEE Trans Biomed Eng, BME-30 : 797-805, 1983. 